\title{
Evaluation Model of Employment and Entrepreneurship of University Students Based on Classification Algorithm
}

\author{
Huaxiang Fu 10 \\ Zhejiang Industry Polytechnic College, Shaoxing, Zhejiang 312000, China \\ Correspondence should be addressed to Huaxiang Fu; 20060030@zjipc.edu.cn
}

Received 14 December 2021; Revised 14 January 2022; Accepted 25 January 2022; Published 16 February 2022

Academic Editor: Gengxin Sun

Copyright $\odot 2022$ Huaxiang Fu. This is an open access article distributed under the Creative Commons Attribution License, which permits unrestricted use, distribution, and reproduction in any medium, provided the original work is properly cited.

\begin{abstract}
As a new data analysis tool, data mining has developed rapidly. Various types of data sets can be used as data mining objects. Faced with more and more data sources and larger amounts of data today, data mining can effectively obtain valuable information from them and can enable people to better predict possible data information in the future, thereby improving work efficiency. Pheromone update uses a combination of global update and local update. The improved algorithm can balance the relationship between ants' exploration and development in the process of searching rules. The government's macroentrepreneurial policy has an important impact on college students' entrepreneurship. Whether the entrepreneurship can obtain government financial support, whether the entrepreneurial process is simple and easy to do, etc., all affect the enthusiasm of college students to start a business and the success of the business. As an important place for college students to live and study, colleges and universities play a vital role in the growth and future development of college students. Major colleges and universities should improve entrepreneurship education, provide materials and manpower such as teaching materials and teachers, and improve the entrepreneurial quality of college students. In addition, colleges and universities should actively establish and improve the entrepreneurial practice platform for college students to help students gain entrepreneurial experience from practice. As the backbone of the social economy, enterprises should play an appropriate role in college students' entrepreneurship. On the one hand, they should actively provide entrepreneurial funds, and they should be willing to give college students experience guidance. Only with the joint efforts of the government, universities, and enterprises, can it be possible to establish a practical and effective support system for undergraduate entrepreneurship, promote undergraduate entrepreneurship, and increase the success rate of undergraduate entrepreneurship.
\end{abstract}

\section{Introduction}

The number of college graduates has continued to increase in recent years [1]. However, the development of the labor market has not been able to provide sufficient jobs to ensure that all graduates can smoothly move to work. At the same time, employers' requirements for the employability of college graduates also follow the quality of talents. With the continuous increase in the promotion of employment, the problem of employment difficulties for college graduates in our country will not be alleviated in the short term [2]. Therefore, improving the employability of college students is one of the important ways to solve the current contradiction in the employment structure. College students are high-level specialized talents who have mastered more scientific and cultural knowledge. Improving the employability of college students, making them fully employed, and ensuring their career development is the key to sustainable social and economic development [3]. Faced with the continuous increase in the number of graduates and the shortage of jobs, the pressure of competition among college students is increasing, and employers are increasingly paying attention to the employability of college graduates [4]. Only those college students with competitive advantages will be in the job hunt. Get the favor of employers. At present, there is a big gap and contradiction between the employability of college students and the recruitment conditions of employers [5]. On the one hand, college students cannot find suitable jobs. A large number of employers report that it is difficult to recruit graduates who meet the requirements of the job [6]. The 
overall employability of graduates and recent graduates is relatively weak. It can be seen that the prominent contradiction of the problem of university employment is that the employability of university graduates cultivated by institutions of higher learning does not meet the recruitment requirements of employers; that is, the employability of college students is insufficient [7].

Faced with the ever-increasing number of university graduates and the shortage of jobs, employers pay more and more attention to the employability of graduates in the recruitment process [8]. The level of employability directly determines whether college graduates can successfully apply for ideal jobs. However, the current situation of the contradiction between supply and demand between social needs and the actual employability of graduates requires the use of various resources to find effective ways to improve the employability of college students [9]. Under the current situation of building a strong country with human capital and rejuvenating the country through science and education, they guide college graduates to actively move to jobs, enhance their own job hunting methods based on the everchanging labor market, and study the employability and training system of college students to promote college students' employment. The improvement of ability is not only closely related to the future of colleges and universities and college students, but also forward-looking strategic thinking about the rapid development of future economy $[10,11]$. Therefore, the research on the employment ability training of college students has important practical significance whether it is for college graduates who are about to set foot on the job, or for the development of colleges and universities, and the harmony and stability of the society. Improving the employability of college students is a necessary condition for employment, and strengthening the cultivation of college students' employability can improve the quality of talent training and make the goal of talent training more concrete and practical [12]. From the perspective of social development, the difficulty of employment of college students is a social problem.

Starting from the overall design of the data mining system, this paper organically divides and recombines the whole process according to the process and functionality of data mining and proposes a mining framework system based on J2EE component technology with good scalability. This paper adjusts the program structure of the traditional ant colony mining algorithm. In the process of rule construction, the attribute node selection probability strategy is modified. The ants in the classification mining algorithm use heuristic functions to improve the efficiency of path selection during the process of searching rules. At the same time, the pheromone in the search is also used as the basis for the selection of the next rule. A new pheromone calculation method is proposed in the calculation of the pheromone. The new pheromone includes not only the attractive part, but also the repulsive part. The algorithm uses high-dimensional storage for each pheromone. The pheromone of only ants can distinguish the pheromone released by different ants. The ant is attracted by the pheromone released by itself but is repelled by the pheromone released by other ants. Using this pheromone calculation method can balance the relationship between exploration and development in the process of ants discovering rules, so that ants tend to explore initially in the process of searching rules. The main place for students to study and live is the school, which is affected by its own limitations, has relatively little contact with the society, and lacks social practical experience. The statistical results of the above survey show that $65.46 \%$ of students said they have not participated in entrepreneurship competitions or entrepreneurship training organized by the school, which undoubtedly lost valuable exercise opportunities for students who want to start their own businesses in the future. $69.17 \%$ of students believe that their entrepreneurial qualities and abilities come from social practice, and students generally agree that they can exercise their comprehensive qualities in social practice activities. Contrary to this, only a small number of students participate in school entrepreneurship competitions, extracurricular lectures, and social practice activities. On the one hand, students are not really interested in these practical activities. It has a certain relationship with the lack of publicity of entrepreneurial competitions and other activities. Therefore, it is necessary to increase the propaganda of practical activities, develop a variety of information release methods in the student group, and increase its influence.

\section{Related Work}

Association analysis is used to describe the connection between different data. Cluster analysis is to divide or combine a set of objects into groups according to the similarities that exist between them and group the clusters so that there is a great similarity between objects of a class and a great difference between objects of different classes. The pattern can be described as the relationship between data sets, the relationship between data in a single data record, or a specific frequency. It mainly includes classification analysis, cluster analysis, association analysis, anomaly analysis, evolution analysis, and specific group analysis [13, 14]. Classification analysis is to establish a certain objective function based on variables of known categories and then classify the target variables according to the original category.

Relevant scholars used the single case study method and analyzed the Massachusetts Institute of Technology as the research object and found that this entrepreneurial ecosystem is composed of many complementary and closely connected projects and centers, student groups, entrepreneurial courses, and many other elements [15]. The interaction of the three forces of entrepreneurial activities, student groups, and entrepreneurial education has become the main driving force for the continuous evolution of this ecosystem [16]. This successful experience of combining entrepreneurial activities and entrepreneurial education to promote entrepreneurial talent training provides a certain reference and reference for the training model of entrepreneurial education in colleges and universities [17].

Relevant scholars used six entrepreneurial models in different directions to find and analyze the common characteristics 
of college students' successful entrepreneurship and proposed that colleges and universities should continue to enrich and improve the content of entrepreneurship education and actively build a school-based entrepreneurial education talent training model [18]. Researchers propose that the entrepreneurial education ecosystem constitutes an important part of the university education ecosystem, including the school microenvironment and the social macroenvironment, and its role is to restrict and regulate entrepreneurial education [19]. To build a good entrepreneurial ecology in colleges and universities, we must adhere to the market orientation, strengthen close cooperation between schools, enterprises, and society under the guidance of national macroeconomic policies, continuously upgrade and optimize the implementation process of entrepreneurship education, and finally realize the cultivation of college students' entrepreneurial awareness.

From the perspective of innovative talent cultivation, relevant scholars explore the localization of entrepreneurial education ecosystem based on innovative talent cultivation [20]. It can be said that different scholars have started from different perspectives and provided us with different perspectives on the construction of the entrepreneurial education ecosystem [21]. These have provided references and references for the author to build an ideal model for the university-led entrepreneurial education ecosystem. Related scholars believe that the entrepreneurial ecosystem advocated by UCLA is composed of related administrative agencies, basic entrepreneurial resources, alumni network, and student associations [22]. The interaction of these four forces promotes the school's entrepreneurial education and entrepreneurial activities. Although the school's entrepreneurial ecosystem is still in the exploratory development stage, it still provides us with a development model that builds an entrepreneurial university in an all-round way by building an entrepreneurial ecosystem, which is worth learning and learning from. Most of the research conducted from this perspective takes advanced foreign entrepreneurial universities as research cases, summarizes and discovers foreign advanced educational experience, and combs out the entrepreneurial ecosystem structure of successful entrepreneurial universities [23].

Relevant scholars believe that it is very important to improve the elements of the entrepreneurial education ecosystem and stabilize the system structure and to promote the sound development of the entrepreneurial education ecosystem $[24,25]$. We need to focus on classroom teaching, scientific research projects, practice platforms, student guidance, and entrepreneurial forums among students and participants in many aspects. Based on the actual situation and training results of the school, the researchers systematically explained the thinking of optimizing the MBA entrepreneurship education ecosystem [26-28]. The two starting points for building the entrepreneurship education ecosystem, namely, internal drive and system internal drive, should pay attention to entrepreneurs. The focus of entrepreneurship education, namely, values, mentality, and methods, should strengthen the construction of entrepreneurial culture in MBA institutions and strengthen contacts and exchanges with the outside of the entrepreneurial education system $[29,30]$.

\section{Method}

3.1. Componentization of the Mining Process. Due to different data sources, such as some data from a database, some from a data warehouse, some from an Excel document, some from an ordinary text file, and some even from a document in a custom format, this component must be designed to carry out relevant classifications.

The database extraction class mainly corresponds to the major relational databases such as Oracle, Mysql, and DB2. Document extraction classes are mainly common data storage documents corresponding to Excel documents or other specifications. The custom extraction class is mainly used to provide the system's future extensibility, so that the system can be easily extended when new data storage methods appear.

Many preprocessing operations are included in this component, such as null value handling, noise filtering, and type conversion. Since this component processes data in standard format, and there is no requirement on the processing order (you can filter noise first and then perform type conversion, or vice versa), you can encapsulate all related data preprocessing operations.

The data modeling component encapsulates various algorithms for mining potential knowledge. In this component, it is divided according to the research content of data mining, and there are different classifications, mainly including the encapsulation of algorithm models such as classification, clustering, association rules, and prediction. Its design form is shown in Figure 1.

\subsection{Data Mining System Based on J2EE. Data mining system} structure is shown in Figure 2. The data mining module is the core of the mining system. Without the support of mining algorithms, no matter how valuable the data is, no new knowledge can be extracted. It can be said that it is not much different from data garbage. The concrete realization of each data mining algorithm model is stored here. It only provides a package for the algorithm, and it is easy to use in other systems to separate it. When there is a new algorithm model, you only need to add the specific implementation of the algorithm in this module in a unified way and associate it with the system.

When the customer builds the specific processing flow of data mining, this module always monitors the user's operation and not only prompts the user's misoperation, but also dynamically records various mining-related operation commands. When mining is executed, this module analyzes the command set of the data mining chain, then executes a series of operations, and feeds back the final processing result to the user. The coordinated control of data extraction component, data preprocessing component, data modeling component, pattern evaluation component, visualization component, etc. is completed by this module. For example, when there is no element of the data extraction component 


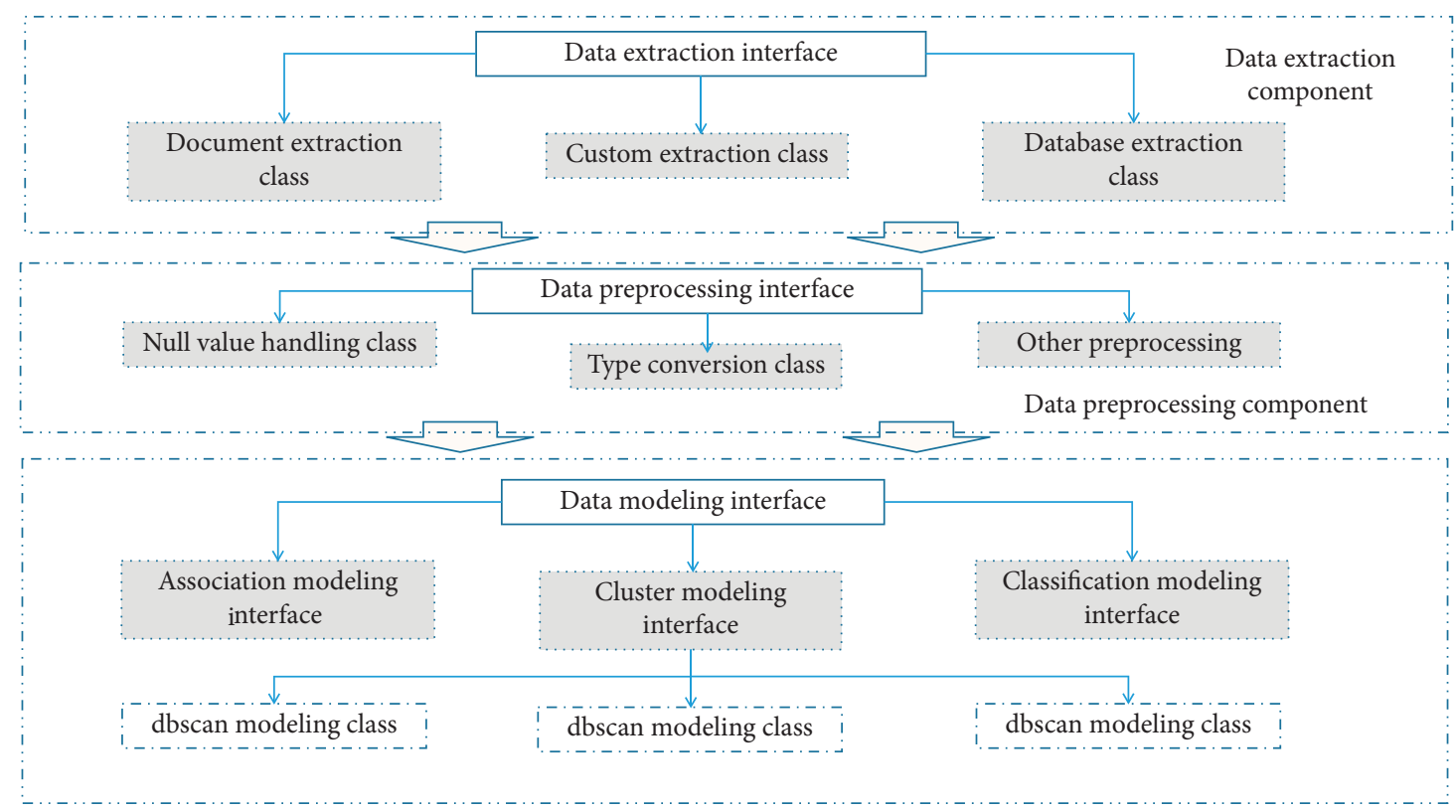

FIgURE 1: Hierarchical structure of data modeling components.

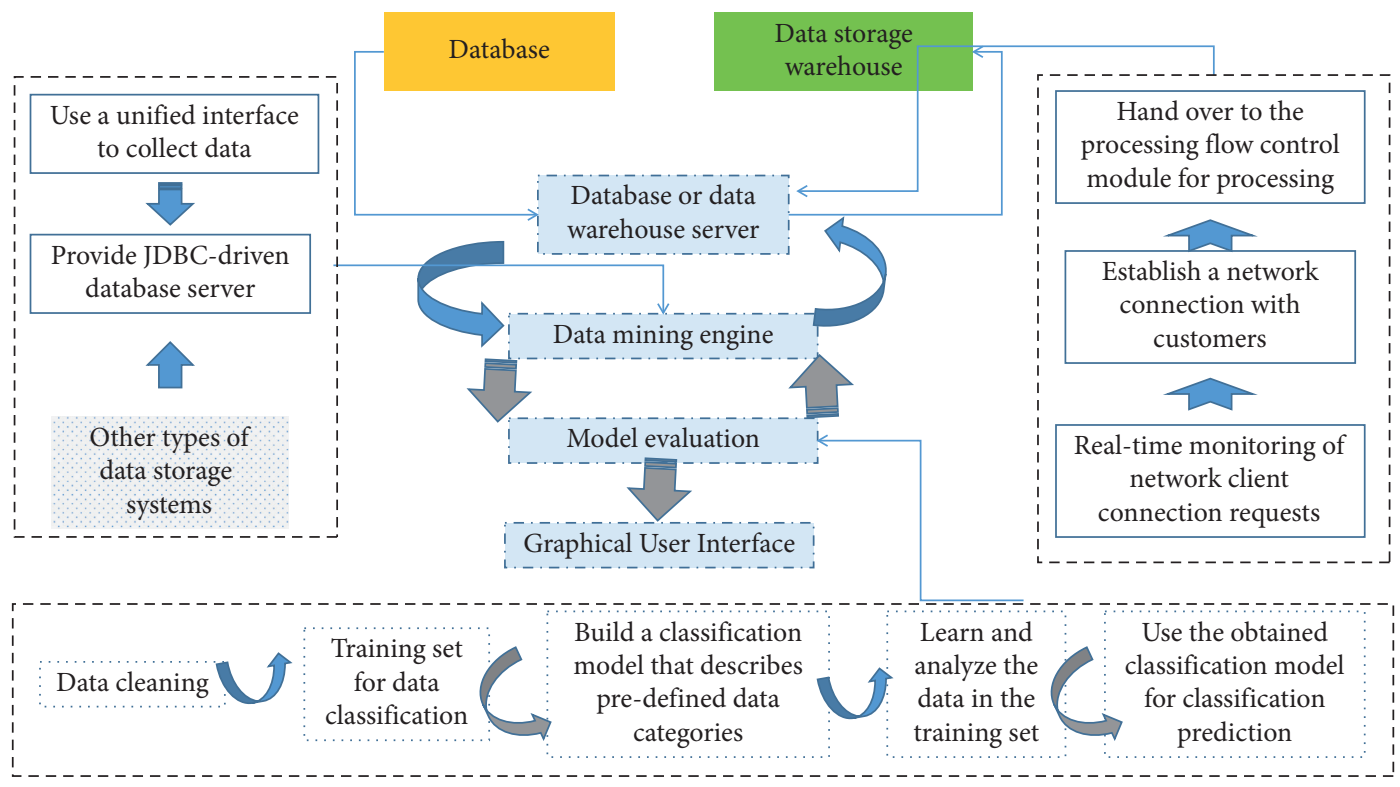

FIGURE 2: Data mining system structure.

in the data mining chain, this module will submit the system after analysis and inform the user that there is no data available for analysis. In addition, the module can automatically detect and report conflicting relationships between elements.

The discovery of knowledge can only be an illusion. Considering the heterogeneity of data distribution, the design of this module can adopt a unified interface to collect data so that the system can be well expanded in the future. Since the analyzed data generally comes from a large relational database, the method of using JDBC to extract database source data is provided here, as long as a database server that provides a JDBC driver can collect data in this way. In addition, for other types of data storage systems (such as Excel files or specific data storage methods adopted by special applications), they can be independently designed and implemented according to the specifications of the data extraction interface.

3.3. Rule Construction Method. Each node obtains the initial pheromone value according to the following formula:

$$
\tau_{i j}(t=-1)=\left(\prod_{i=0}^{a-1} b_{i}\right)^{-1}
$$


In the formula, $a$ represents the total number of attributes of the training set samples, and $b_{i}$ is the number of values in the range of attribute $A_{i}$.

This paper proposes a new pheromone calculation method based on the principle of pheromone attraction and repulsion and applies it to a new transition probability calculation. The new pheromone includes an attraction part and a repulsion part, and the algorithm uses high-dimensional storage. The pheromone of each ant can distinguish the pheromone released by different ants. Ants are attracted by the pheromone released by themselves but are repelled by the pheromone released by other ants. The weight of attraction is defined as

$$
\Lambda_{i j}^{k}(t)=\left[\tau_{i j}^{k}(t) \bullet \tau_{i j}^{k}(t+1)\right] / \tau_{i u}^{k}(t) .
$$

The weight for rejection is defined as

$$
\Phi_{i j}^{k}(t)=\prod_{i j}^{k}(t) \bullet \prod_{i u}^{k}(t) / N_{i}^{k}(t),
$$

where

$$
\prod_{i j}^{k}(t)=\tau_{i j}^{m}(t) \bullet \tau_{i j}^{m}(t+1) .
$$

The pheromone calculation method at $\mathrm{Term}_{i j}$ position is

$$
\tau_{i j}(t)=\left[\Lambda_{i j}^{k}(t)\right]^{a} \cdot\left[\Lambda_{i j}^{k}(t-1)\right]^{-1} /\left[\Lambda_{i u}^{k}(t)\right]^{a-1} .
$$

The algorithm is realized by the continuous increase of the attraction weight and the continuous decrease of the repulsion weight. In the initial stage of the algorithm, because the pheromone left by other ants is more than the pheromone left by the ant itself, ants tend to untraveled roads, which is conducive to exploring new paths and discovering new rules. After that, the pheromone left by the ant itself will continue to increase.

\subsection{Rule Pruning and Pheromone Update Method}

3.4.1. Rule Pruning. Due to the influence of noise in the data, some items in the mining rules may be anomalies in the training data. Pruning can solve the problem of overfitting data samples. Repeatedly judging whether retaining a certain condition in the mining rule can improve the quality of the rule, if it cannot, delete the condition; otherwise keep the condition, until any condition is deleted from the rule; the quality of the rule cannot be improved. Or there is only one condition left. The pruning method can improve the accuracy of the rules and avoid overfitting the training set data. On the other hand, pruning can also make the rules more concise and increase intelligibility, because a short rule is usually easier to understand than a long rule. The quality calculation of the rules of this paper is given by the following formula:

$$
Q= \begin{cases}-1, & 2 T N+F P=0, \\ T P /(F N-T P), & F N-T N=0, \\ T P /(T P-F P), & T N-F P=0, \\ T P /(T P+F P), & F P-F N=0, \\ 1, & T N+F P-2 F N=0 .\end{cases}
$$

3.4.2. Pheromone Update. When a rule list is searched, the pheromone of the condition node that appears in the rule list is updated according to the following formula:

$$
\tau_{i j}(t+1)=\tau_{i j}(t-1)-\tau_{i j}(t) \bullet Q .
$$

The volatilization of the pheromone of the attribute node outside the rules is achieved by standardizing the pheromone value of each attribute node:

$$
\tau_{i j}(t+1)=\tau_{i j}(t-1) \bullet \prod_{i, j=0}^{a-1} \tau_{i j}(t) .
$$

\section{Results and Analysis}

4.1. Analysis of Reliability and Validity. The "Questionnaire Survey on College Students' Entrepreneurship Support System" used in this research aims to investigate college students' understanding of self-employment and their support for self-employment, which involves many students' real thoughts and attitudes. In order to ensure the high validity and reliability of this questionnaire, before the formal questionnaire is formed, the prepared questionnaire should be tested and analyzed, and the reliability and validity of the test results should be analyzed in time.

4.1.1. Test and Analysis of Questionnaire Reliability. The coefficient of reliability commonly used in the attitude scale method is $\alpha$ (Cronbach) reliability coefficient. The $\alpha$ reliability coefficient is between 0 and 1 . If the value of the $\alpha$ reliability coefficient is between 0.60 and 0.65 , it is best not to; if the value of the $\alpha$ reliability coefficient is between 0.65 and 0.70 , it is the minimum acceptable value; if the value of the $\alpha$ reliability coefficient is above 0.70 , it means that the reliability of the scale or test is very good. In general, we think that if the $\alpha$ reliability coefficient is above 0.60 , it can be considered that the reliability of the questionnaire is good. This questionnaire uses SPSS18.0 software to test the reliability. After testing, the $\alpha$ reliability coefficient value is above 0.8 , and the reliability is good. The test result of the $\alpha$ reliability coefficient is shown in Figure 3.

4.1.2. Test and Analysis of Questionnaire Validity. (1) It mainly involves the two aspects of whether the factors are comprehensive and whether the relationship between the factors is appropriate. The most commonly used method to evaluate the validity of the structure is factor analysis, that is, the KMO test validity and the Bartlett spheroid test. (2) If the $\mathrm{KMO}$ value is greater than 0.8 , the validity is very high; if the 


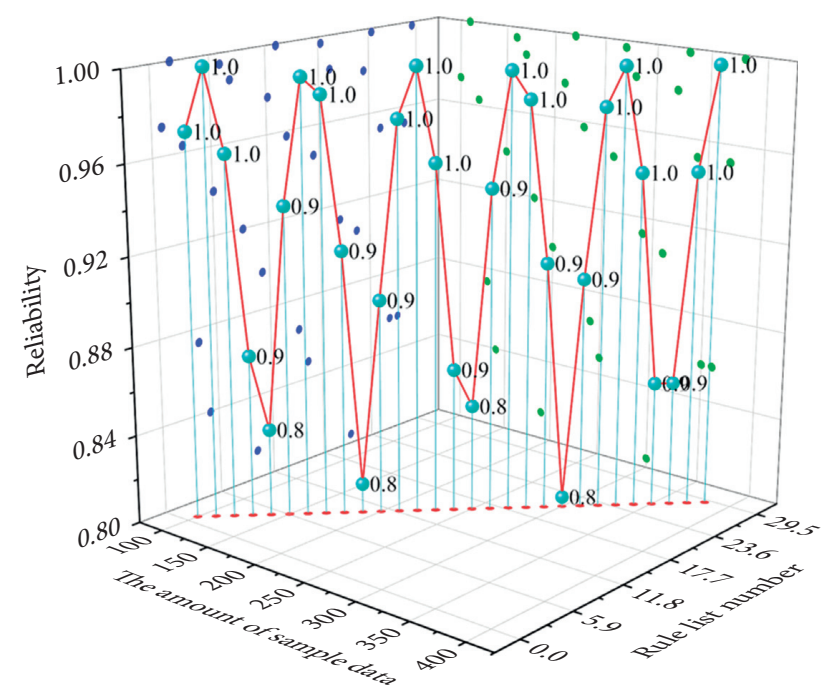

Figure 3: Detection of $\alpha$ reliability coefficient.

KMO value is greater than 0.7 , the validity is good; if the $\mathrm{KMO}$ value is greater than 0.6 , the validity is acceptable; if the KMO value is less than 0.6 , the validity is not too good. If the $\mathrm{KMO}$ value is less than 0.5 , it means that the validity is completely unsatisfactory, and the items need to be revised. (3) This questionnaire uses SPSS17.0 software to test the validity. After testing, the KMO value is above 0.72 , reaching the significance level $(p<0.05)$, and the null hypothesis can be rejected. Therefore, it is judged that the validity of this questionnaire is good. The KMO test results are shown in Figure 4.

4.2. Evaluation of Entrepreneurial Interest and Timing. From the statistical results of the questionnaire survey, college students have a higher enthusiasm for independent entrepreneurship, which shows that, in the current fierce social competition, college students have a stronger sense of independence and self-improvement, and they also have a strong desire for career pursuit. Figure 5 shows the proportion of college students' interest in self-employment.

Although the vast majority of students have shown great interest in self-employment, only $3.71 \%$ of college students have started self-employment, but nearly $65.55 \%$ of students have no current entrepreneurial ideas. Among the seniors, those who have no idea of self-employment even reached $54.55 \%$ and $46.81 \%$. Most students have a wait-and-see attitude towards self-employment, only staying at the lower level of interest, and did not take actual entrepreneurial practice activities. After market opportunities appear, there are still a small number of people who directly seize the opportunity to start their own businesses. Most people choose to practice for a few years or accumulate certain resources before starting a business. It can be seen from this point that most students still maintain a very cautious and rational attitude towards self-employment. In the game with other relatively stable career choices, self-employment is obviously not the first choice. This also shows that college students still lack the sense of adventure and entrepreneurial

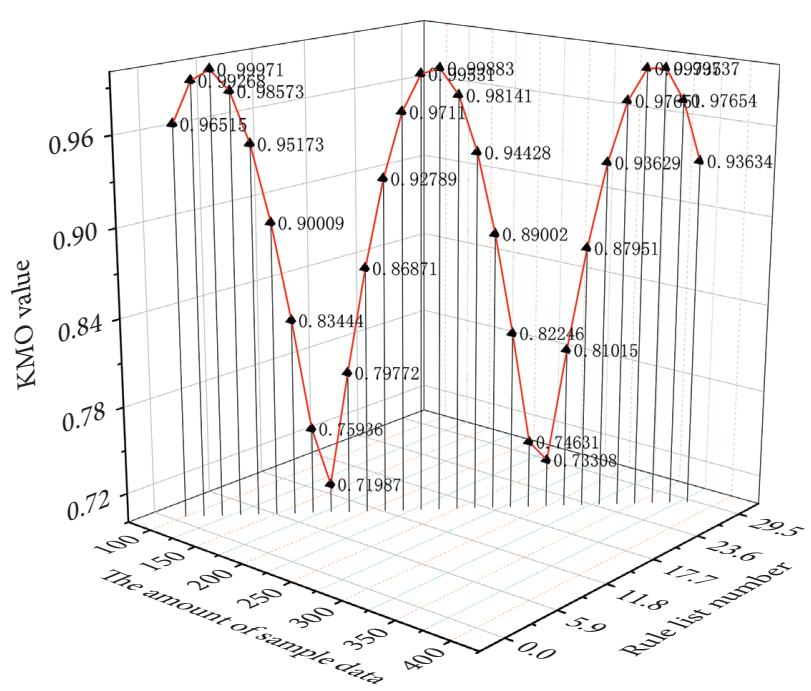

FIGURE 4: KMO inspection results.

spirit. On the other hand, with the continuous improvement of college students' knowledge, their career choices are becoming more and more diversified. Figure 6 shows the timing of college students' self-employment choices.

4.3. Self-Employment Ability and Quality Evaluation. $69.17 \%$ of students believe that their entrepreneurial qualities and abilities come from social practice, $14.65 \%$ of students believe that it is self-directed learning, $8.23 \%$ of students choose the influence of relatives and friends, and only $7.96 \%$ of students choose school education. This also reflects from the side that the effectiveness of the school's entrepreneurship education has not achieved the expected results. Self-employment is an action that closely combines sociality and practicality, so the part-time social activities or internships inside and outside the school that students participate in during school can fully exercise the quality and ability of students to a large extent. However, the school's entrepreneurship education for college students is still of great significance. In fact, most of the time that students study and grow up at the university level is in school, so the school still has a lot to do in cultivating college students' selfemployment awareness and training college students' selfemployment ability. Figure 7 shows the distribution of entrepreneurial abilities of 380 college students. It can be seen that the entrepreneurial ability of college students is lower than 0.84 , which is not very high.

\subsection{Evaluation of Government and University Support.} According to the survey statistics on the aspects of government support for college students' self-employment, $48.1 \%$ of students believe that the government should set up a science and technology entrepreneurship fund for college students to support students' self-employment; $28.39 \%$ of students choose policy support; $3.07 \%$ of students choose to promote and encourage. In the survey statistics on what measures schools should take to encourage college students to start their own businesses, $62.3 \%$ of students' first choice 


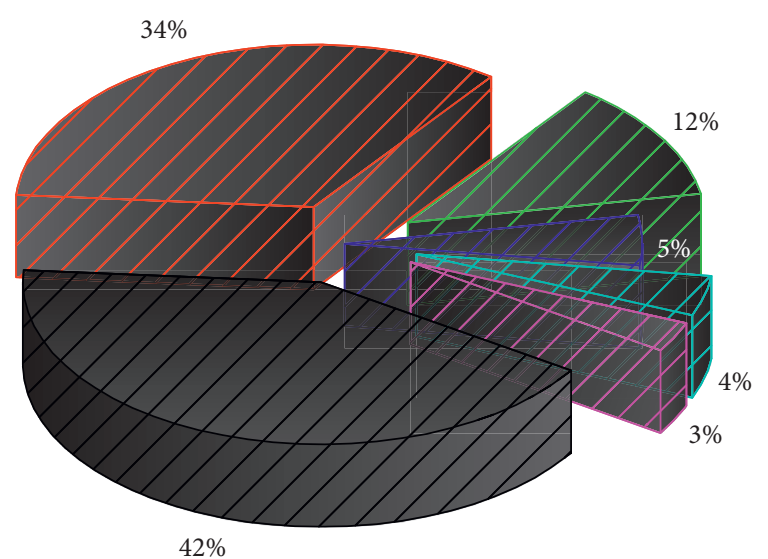

IV.L. Very interested

'Y 7.2 . More interested

IV. $\angle$. Interested

IV.C. Generally interested

ry. $\angle$. Not interested

IVIC. Others

Figure 5: Proportion of college students' interest in selfemployment.

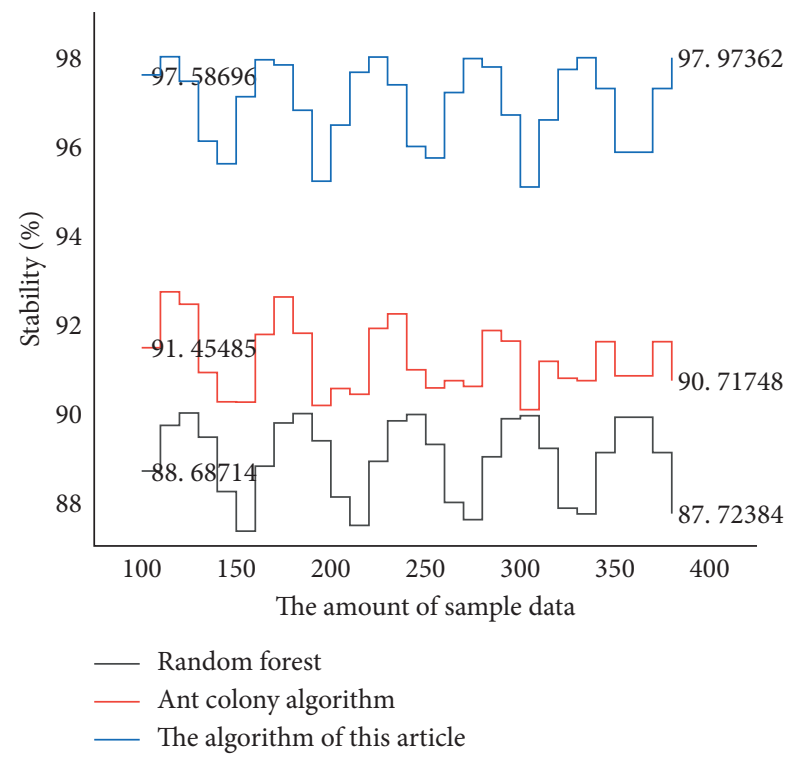

FIGURE 6: Stability evaluation of the timing of self-employment by college students.

is to be included in the university science and technology park; $21.07 \%$ of the students believe that the school should provide corresponding supporting funds. What most students want most is socialized professional incubator support and systematic services. Once the venture capital is resolved, only a united and harmonious entrepreneurial team can go further and the company can develop better. The relationship between measure support and the success rate of college students' independent entrepreneurship is shown in Figure 8.

4.5. Evaluation of Environmental Support. Generally speaking, students still agree with the entrepreneurial environment created in a certain area, which is inseparable

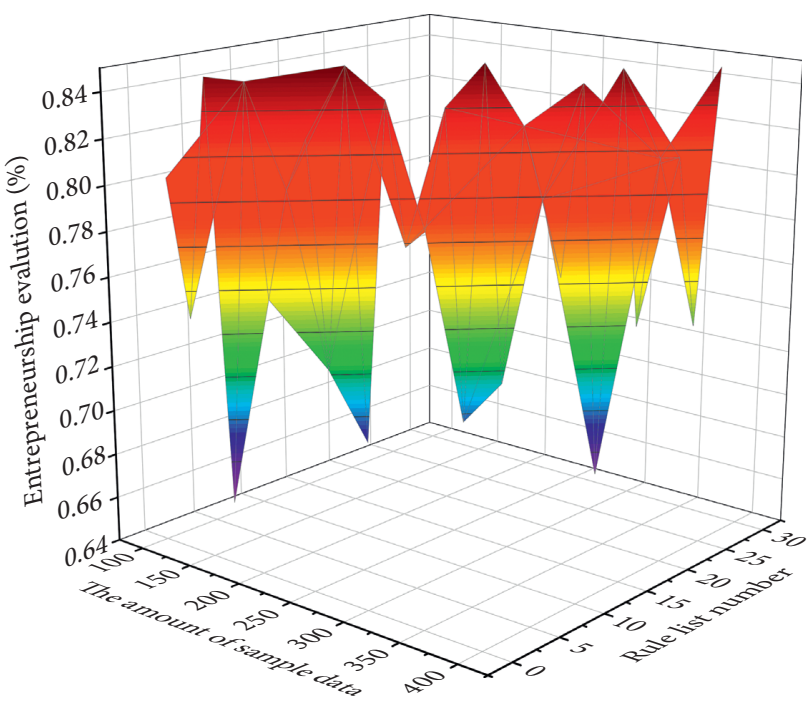

Figure 7: Distribution of entrepreneurial ability of 380 college students.

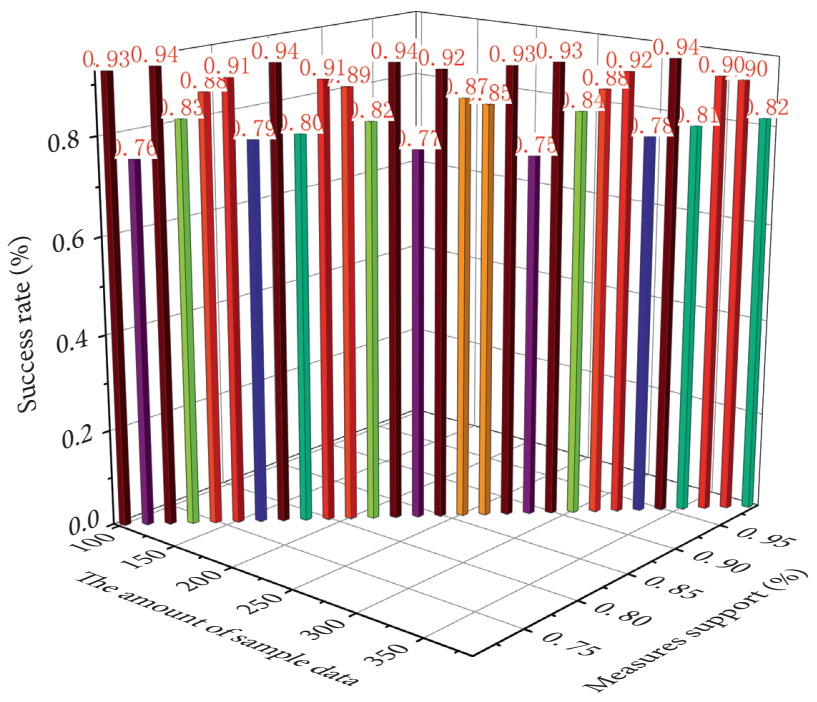

Figure 8: The relationship between measure support and the success rate of college students' self-employment.

from the support and services of all parties in a certain area. There are many colleges and universities in a certain area, with nearly 280,000 college students, who have strong talent support capabilities. A certain local government has launched a nationwide entrepreneurial initiative and regarded it as a strategic measure, trying to maximize the creative vitality of the society. It not only supports the selfemployment of college students, but also introduces new regulations to encourage and support the independent resignation, resignation, early retirement, and entrepreneurship of employees of government agencies and institutions, as well as helping enterprises to start their own businesses. The municipal government has adjusted 30 million yuan from the unemployment insurance special fund surplus over the years as entrepreneurial support funds, which is mainly used to support the development of small 


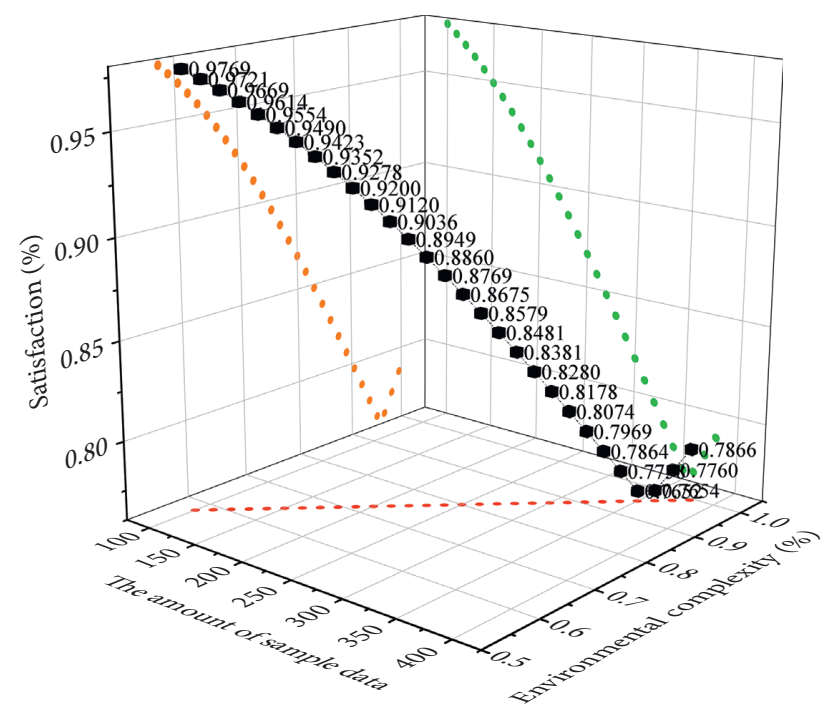

FIGURE 9: Evaluation of satisfaction with the entrepreneurial environment of college students.

and micro enterprises in the city and the construction of entrepreneurial incubation bases (parks) and conduct entrepreneurship training and entrepreneurship training. Evaluation of satisfaction with the entrepreneurial environment of college students is shown in Figure 9.

\section{Conclusion}

A new ant colony algorithm based on the principle of pheromone attraction and repulsion is proposed, and a new pheromone calculation method and probability transfer formula are designed. The algorithm's iterative sequence is updated. The algorithm's pheromone update uses a combination of global and local updates. The pheromone in the ant's search process includes both attractive and repulsive parts. The relationship between exploration and development makes ants tend to explore in the initial stage of the search process and tend to develop in the later stage of the search. This article uses a questionnaire survey to investigate the overall situation of college students' entrepreneurship and statistically analyze the survey data. This survey focuses on the main problems that exist in the process of college students' entrepreneurship. Through statistical analysis, it is found that colleges and universities lack support policies with their own school characteristics, and many colleges and universities have not formulated support policies based on their own schools; entrepreneurial support funding channels are single, and the problem of college students' entrepreneurial funds is more serious; at the same time, college students themselves are easily caused by the lack of entrepreneurial practical experience. On the basis of cultivating the inner qualities of college students, a sound social support system and corresponding entrepreneurial atmosphere are needed. What is important is that the entrepreneurial support system complements the lack of entrepreneurial ability of college students. The most important subjects in this system are the government, enterprises, and universities.
Only based on the promotion and positive influence of entrepreneurial public opinion, entrepreneurship guidance, entrepreneurship education, entrepreneurial funds, and entrepreneurial policies, can the linkage mechanism of the university student entrepreneurship support system proceed, and it can help university students clear up the obstacles to entrepreneurship and promote university students to start their own businesses.

\section{Data Availability}

The data used to support the findings of this study are available from the corresponding author upon request.

\section{Conflicts of Interest}

The authors declare that they have no known competing financial interests or personal relationships that could have appeared to influence the work reported in this paper.

\section{Acknowledgments}

This work was supported by Zhejiang Industry Polytechnic College.

\section{References}

[1] L. Song, H. Wang, and P. Chen, "Step-by-step fuzzy diagnosis method for equipment based on symptom extraction and trivalent logic fuzzy diagnosis theory," IEEE Transactions on Fuzzy Systems, vol. 26, no. 6, pp. 3467-3478, 2018.

[2] J. M. Moyano, E. L. Gibaja, K. J. Cios, and S. Ventura, "Review of ensembles of multi-label classifiers: Models, experimental study and prospects," Information Fusion, vol. 44, pp. 33-45, 2018.

[3] M. R. Alam, M. T. A. Begum, and K. M. Muttaqi, “Assessing the performance of ROCOF relay for anti-islanding protection of distributed generation under subcritical region of power imbalance," IEEE Transactions on Industry Applications, vol. 55, no. 5, pp. 5395-5405, 2019.

[4] W. Zhao, S. Han, W. Meng, D. Sun, and R. Q. Hu, "BSDP: Big sensor data preprocessing in multi-source fusion positioning system using compressive sensing," IEEE Transactions on Vehicular Technology, vol. 68, no. 9, pp. 8866-8880, 2019.

[5] B. T. Sivrikaya, F. Cebi, H. H. Turan, N. Kasap, and D. Delen, "A fuzzy long-term investment planning model for a GenCo in a hybrid electricity market considering climate change impacts," Information Systems Frontiers, vol. 19, no. 5, pp. 975-991, 2017.

[6] J. Wiklund and S. Dean, "Entrepreneurial orientation and small business performance: A configurational approach," Journal of Business Venturing, vol. 20, pp. 71-91, 2015.

[7] L. Ali, A. Niamat, J. A. Khan et al., "An optimized stacked support vector machines based expert system for the effective prediction of heart failure," IEEE Access, vol. 7, pp. 54007-54014, 2019.

[8] H. Liu, X. Wu, and S. Zhang, "Neighbor selection for multilabel classification," Neurocomputing, vol. 182, pp. 187-196, 2016.

[9] Z. Chen, X. Pei, M. Yang, L. Peng, and P. Shi, "A novel protection scheme for inverter-interfaced microgrid (IIM) operated in islanded mode," IEEE Transactions on Power Electronics, vol. 33, no. 9, pp. 7684-7697, 2018. 
[10] Y. Guo, F.-L. Chung, G. Li, and L. Zhang, "Multi-label bioinformatics data classification with ensemble embedded feature selection," IEEE Access, vol. 7, pp. 103863-103875, 2019.

[11] H. M. Elzarka, H. Yan, and D. Chakraborty, "A vague set fuzzy multi-attribute group decision-making model for selecting onsite renewable energy technologies for institutional owners of constructed facilities," Sustainable Cities and Society, vol. 35, pp. 430-439, 2017.

[12] L. Révészovà, "Designing modern informatics education for future managers and advanced users according to their knowledge base," E + M: Ekonomie a Management Praha Czech Republic, vol. 19, no. 4, pp. 186-201, 2016.

[13] S. Chen, H. Ge, J. Li, and M. Pecht, "Progressive improved convolutional neural network for avionics fault diagnosis," IEEE Access, vol. 7, pp. 177362-177375, 2019.

[14] A. Osojnik, P. Panov, and S. Džeroski, "Multi-label classification via multi-target regression on data streams," Machine Learning, vol. 106, no. 6, pp. 745-770, 2017.

[15] R. Escudero, J. Noel, J. Elizondo, and J. Kirtley, "Microgrid fault detection based on wavelet transformation and Park's vector approach," Electric Power Systems Research, vol. 152, pp. 401-410, 2017.

[16] A. Zhu, C. Xu, Z. Li, J. Wu, and Z. Liu, "Hybridizing grey wolf optimization with differential evolution for global optimization and test scheduling for 3D stacked SoC," Journal of Systems Engineering and Electronics, vol. 26, no. 2, pp. 317-328, 2015.

[17] L. Suganthi, S. Iniyan, and A. A. Samuel, "Applications of fuzzy logic in renewable energy systems - a review," Renewable and Sustainable Energy Reviews, vol. 48, pp. 585-607, 2015.

[18] H. Malik and S. Mishra, "Artificial neural network and empirical mode decomposition based imbalance fault diagnosis of wind turbine using TurbSim, FAST and Simulink," IET Renewable Power Generation, vol. 11, no. 6, pp. 889-902, 2017.

[19] T. Al-Khateeb, M. M. Masud, K. M. Al-Naami et al., "Recurring and novel class detection using class-based ensemble for evolving data stream," IEEE Transactions on Knowledge and Data Engineering, vol. 28, no. 10, pp. 2752-2764, 2016.

[20] A. Kulshrestha, O. P. Mahela, M. K. Gupta et al., "A hybrid fault recognition algorithm using stockwell transform and wigner distribution function for power system network with solar energy penetration," Energies, vol. 13, no. 14, p. 3519, 2020.

[21] Q. Al-Tashi, S. J. Abdul Kadir, H. M. Rais, S. Mirjalili, and H. Alhussian, "Binary optimization using hybrid grey wolf optimization for feature selection," IEEE Access, vol. 7, pp. 39496-39508, 2019.

[22] J. Liu, Z. Zhao, C. Tang, C. Yao, C. Li, and S. Islam, "Classifying transformer winding deformation fault types and degrees using FRA based on support vector machine," IEEE Access, vol. 7, pp. 112494-112504, 2019.

[23] J. Huang, G. Li, Q. Huang, and X. Wu, "Learning label-specific features and class-dependent labels for multi-label classification," IEEE Transactions on Knowledge and Data Engineering, vol. 28, no. 12, pp. 3309-3323, 2016.

[24] N. El-Naily, S. M. Saad, T. Hussein, and F. A. Mohamed, “A novel constraint and non-standard characteristics for optimal over-current relays coordination to enhance microgrid protection scheme," IET Generation, Transmission \& Distribution, vol. 13, no. 6, pp. 780-793, 2019.

[25] H. Faris, M. A. Hassonah, A. M. Al-Zoubi, S. Mirjalili, and I. Aljarah, "A multi-verse optimizer approach for feature selection and optimizing SVM parameters based on a robust system architecture," Neural Computing \& Applications, vol. 30, no. 8, pp. 2355-2369, 2018.

[26] M. Tian, L. Zhang, P. Guo et al., "Data dependence analysis for defects data of relay protection devices based on apriori algorithm," IEEE Access, vol. 8, pp. 120647-120653, 2020.

[27] J. Huang, G. Li, S. Wang, Z. Xue, and Q. Huang, "Multi-label classification by exploiting local positive and negative pairwise label correlation," Neurocomputing, vol. 257, pp. 164-174, 2017.

[28] J. J. Q. Yu, Y. Hou, A. Y. S. Lam, and V. O. K. Li, "Intelligent fault detection scheme for microgrids with wavelet-based deep neural networks," IEEE Transactions on Smart Grid, vol. 10, no. 2, pp. 1694-1703, 2019.

[29] H. M. Zawbaa, E. Emary, C. Grosan, and V. Snasel, "Largedimensionality small-instance set feature selection: A hybrid bio-inspired heuristic approach," Swarm and Evolutionary Computation, vol. 42, pp. 29-42, 2018.

[30] M. Shafiullah, M. A. Abido, and Z. Al-Hamouz, "Waveletbased extreme learning machine for distribution grid fault location," IET Generation, Transmission \& Distribution, vol. 11, no. 17, pp. 4256-4263, 2017. 